\title{
Microtransfusion and viral exposure in uninfected infants born to HIV-infected women Julia Warning ${ }^{* 1}$, John Ziegler ${ }^{1}$ and Rosemary Ffrench ${ }^{2}$
}

\author{
Address: ${ }^{1}$ School of Women's and Children's Health, University of New South Wales, Randwick, New South Wales, 2052, Australia and ${ }^{2}$ Viral \\ Immunology Group, Burnet Institute, Melbourne, 3001, Australia \\ * Corresponding author
}

from Fourth Dominique Dormont International Conference. Host-Pathogen Interactions in Chronic Infections

Paris, France. 13-15 December 2007

Published: 9 April 2008

Retrovirology 2008, 5(SuppI I):O2I doi:I0.II86/I742-4690-5-SI-O2I

This abstract is available from: http://www.retrovirology.com/content/5/SI/O2I

(C) 2008 Warning et al.; licensee BioMed Central Ltd.

\section{Background}

HIV-specific cellular immune responses have been detected in some uninfected infants born to HIV-infected women, indicating transient virus exposure or replication has occurred. Small quantities of maternal blood pass into the infant's circulation during childbirth, termed "microtransfusion", potentially facilitating viral exposure. We sought to determine the occurrence of microtransfusion and HIV-specific immune responses as an indicator of viral exposure in a cohort of uninfected infants born to HIV-infected women, in the context of interventions.

\section{Materials and methods}

46 uninfected infants born to HIV-infected women were included in this study. Infants were grouped according to interventions utilised by the mother: none or antiretroviral therapy (ART; group A, $\mathrm{n}=16$ ), ART with elective caesarean section (elCS; group $\mathrm{B}, \mathrm{n}=12$ ), highly active antiretroviral therapy (HAART) only (group $\mathrm{C}, \mathrm{n}=7$ ), and HAART with elCS (group D, $n=11$ ). HLA-A and -B alleles were typed for all mother-baby pairs to identify the noninherited maternal alleles (NIMA). To detect microtransfusion, sensitive flow cytometry and qPCR-based assays specific for the NIMA were developed and applied to umbilical cord blood and peripheral blood collected from HIV-uninfected infants born to HIV-infected women. HIV-specific immune responses were detected using the chromium51-release and IFN- $\gamma$ ELISpot assays.

\section{Results}

Microtransfusion was detected in the umbilical cord blood of 10 of 11 infants tested, and remained detectable in the peripheral blood of 4 of the 10 infants up to 1 week of age. 10 of 46 infants had HIV-specific cellular immune responses, 7 were in group A, 2 in group B, and 1 in group $\mathrm{C}$, while no infants in group $\mathrm{D}$ had detectable responses ( $p=0.02$, Fisher's exact test). Blood samples from 3 of these 10 infants were available for the analysis of microtransfusion. Microtransfused maternal cells were present in the umbilical cord blood of all 3 infants, and remained in the peripheral blood of 1 infant up to one week of age. The remaining 7 infants with microtransfusion did not have detectable HIV-specific immune responses.

\section{Conclusions}

In this study, the number of infants with detectable HIVspecific immune responses decreases with the use of MTCT interventions, suggesting that these interventions reduce viral exposure in these infants. This is the first study to observe both microtransfusion and HIV-specific immune responses in uninfected infants, indicating that the passage of maternal blood may be a source of viral exposure and subsequent development of potentially protective HIV-specific immune responses in infants born to HIV-infected women. 